www.jmscr.igmpublication.org

Impact Factor 5.84

Index Copernicus Value: 83.27

ISSN (e)-2347-176x ISSN (p) 2455-0450

crossref DOI: _https://dx.doi.org/10.18535/jmscr/v5i3.04

\title{
A Prospective Analysis of Functional Outcome of Unstable Trochanteric Fractures Managed with Proximal Femoral Nail
}

\author{
Authors \\ Karthikeyan N, Vanangamudi K \\ GMKMCH, Salem, TN
}

\begin{abstract}
Aim: The aim of our study is to analyze the functional outcome of unstable intertrochanteric fractures managed with Proximal Femoral nailing.

Patients and Methods: Twenty four patients with unstable intertrochanteric fractures were selected for our prospective study. All were treated with fixation with Proximal femoral nails. The functional outcome of these patients were analyzed using Harris hip score.

Results: At three months follow up $45 \%$ of patients had good to excellent results which at six months improved to $91 \%$. In all patients fracture united by six months. We had shortening in six patients, varus collapse in three patients and implant failure in one patient.

Conclusion: Unstable intertrochanteric fractures require reduction and fixation with an intramedullary load bearing implant which ensures early return to preinjury activity which is important especially in the elderly people. Proximal femoral nail offers the solution with less morbidity.
\end{abstract}

\section{Introduction}

As modern medicine expands its reach, the life expectancy increases all around the globe. With this increasing geriatric population the incidence of hip fractures are also raising. Most of these are unstable intertrochanteric fractures due to age related Osteoporosis.

With ever increasing number of two wheelers on the road coupled with apathy towards road safety, we get comminuted unstable intertrochanteric fractures in young patients involved in RTA.

The young and the old alike need to be returned to preinjury activity level as early as possible. This is especially important for the elderly as they are at risk of immobility related complications. This requires operative management with a device which offers less perioperative and post operative morbidity, early weight bearing and fracture union.

Though the Dynamic or Sliding Hip Screw with Side plate device has long been the gold standard for the intertrochanteric fractures, it is now being replaced largely with Cephalo medullary nails for the unstable trochanteric fractures. The Proximal Femoral Nail system offers adequate mechanical and biological environment for the unstable trochanteric fractures to unite.

\section{Patients and Methods}

In our institution at Govt Mohan Kumaramangalam Medical College, Salem, we selected 24 cases of unstable intertrochanteric fractures for 
this prospective study. All cases enrolled were managed with Proximal femoral nail. Of them, 15 were male and 9 were female patients.

All the selected patients had unstable intertrochanteric fractures as classified by $\mathrm{AO}$ system of classification namely $31 \mathrm{~A} 2.2$ to $31 \mathrm{~A} 3.3$ The age of the patients ranges from 27 years to 75 years with an average age of 52.45 years. Right hip was involved in 11 patients and left hip was involved in 13 patients. Patients with pathological fractures or with increased femoral bow were not included in our study.

The study was conducted from May2010 to September 2014. The mean follow up period was 8.58 months. These cases were studied on the basis of mechanism of injury, classification and treatment with proximal femoral nail and their surgical and functional outcome with or without residual complication.

After preoperative assessment by the anaesthetic team and with informed written consent, patients were taken up for surgery. All patients were operated under regional anaesthesia. With patient in fracture table, under $\mathrm{C}$ arm guidance, closed reduction performed and proceeded. In cases where closed reduction could not be obtained, minimal open reduction performed. Type A2 fractures were fixed with short $250 \mathrm{~mm}$ Proximal femoral nails and Type A3 fractures were fixed with Long Proximal femoral nails. In all cases, distal locking performed.

All patients were given parentral antibiotics perioperatively. Static Quadriceps strengthening exercises were started from second post operative day. Non weight bearing mobilization and hip and knee assisted exercises started from third day.

Non weight bearing walking were encouraged from as early as third day. Partial weight bearing started from 2 to 4 weeks. After clinical and radiological union, full weight bearing started.

Patients were followed up every 4 weeks regularly for twelve months. Both clinical and radiological evaluation were carried out. Clinical union was observed as the absence of pain and tenderness with full weight bearing.
The patients were evaluated with Modified Harris hip scoreat $3^{\text {rd }}$ month and $6^{\text {th }}$ month and were categorized according to the scores they attained.

\section{Observations and Results}

The average age of the patient in our study is 52.45 years. Mode of injury was accidental fall in 13 patients and Road traffic accident in other patients.

16 patients had Type A2 fractures and the other 8 had Type A3 fractures. Six patients who had Type A33 were managed with Long nails and the rest with Short nails.

The mean duration of surgery was 58 minutes.

Intraoperative complications we encountered were

\begin{tabular}{|l|c|}
\hline Complication & Number of patients \\
\hline $\begin{array}{l}\text { Fracture displacement by nail } \\
\text { insertion }\end{array}$ & 3 \\
\hline Failure to get anatomical reduction & 1 \\
\hline Difficulty to placederotation screw & 3 \\
\hline Breakage of guide wire & 1 \\
\hline Breakage of drill bit & 0 \\
\hline Varus angulation & 3 \\
\hline
\end{tabular}

The mean follow up period was 8.58 months. The patients were evaluated using Modified Harris Hip Score. The clinical assessment included Gait, Pain, Deformity, Shortening, Range of movements, Ability to sit cross legged, Ability to squat and Return to pre-injury occupation.

Radiologically assessed were Signs of union, Varus collapse, Amount of lateral slide, Screw cut out, 'Z' effect, Implant failure and loss of fixation

\section{Harris Hip Score}

\begin{tabular}{|c|c|c|c|c|}
\hline \multirow{2}{*}{$\begin{array}{l}\text { Functional } \\
\text { outcome }\end{array}$} & \multicolumn{2}{|c|}{$3^{\text {rd }}$ month } & \multicolumn{2}{|c|}{$6^{\text {th }}$ month } \\
\hline & $\begin{array}{c}\text { Number of } \\
\text { patients }\end{array}$ & $\begin{array}{c}\text { Percen } \\
\text { tage }\end{array}$ & $\begin{array}{l}\text { Number } \\
\text { of patients }\end{array}$ & $\begin{array}{c}\text { Percent } \\
\text { age }\end{array}$ \\
\hline Excellent & 2 & 8.33 & 12 & 50 \\
\hline Good & 9 & 37.5 & 10 & 41.66 \\
\hline Fair & 6 & 25 & 1 & 4.16 \\
\hline Poor & 6 & 25 & 1 & 4.16 \\
\hline
\end{tabular}

We had shortening in 8 patients, varus collapse in 4 patients. One patient developed superficial surgical site infection and was appropriately managed. 
One patient encountered implant failure which resulted in varusmal union. $\mathrm{Z}$ effect was seen in one patient.

In all the cases fracture union was achieved. The average time for fracture union was 11.12 weeks(range : 8 - 22weeks).

\section{Discussion}

The success of surgical management of intertrochanteric fracture depends on physiological age of the patient, co morbid conditions and their control, bone quality, fracture anatomy, injury to surgery interval, method of fixation and stability of fixation.

Though the conventional Sliding Hip Screw system gives good results in stable fractures, it can not allow early weight bearing in an elderly patient with unstable intertrochanteric fracture in the osteoporotic bone.

The intramedullary Proximal Femoral Nails are biomechanically stronger and offer controlled axial telescoping and rotational stability.

In trochanteric fractures, Intramedullary implants withstand higher static and a several-fold higher cyclical loading than DHS types of implants. Hence, the fracture heals even without the primary restoration of the medial support. The implant temporarily compensates for the function of the medial column.

In A1 and A2 fractures axial loading leads to fracture impaction, whereas in A3 fractures such impaction does not occur, and medial displacement of the distal fragment of the fracture is common due to the instability. Due to its position close to the weight-bearing axis, the stress generated on the intramedullary implants is negligible. The PFN also acts as a buttress in preventing the medialisation of the shaft.

Biomechanically, compared to a laterally fixed side plate, the intramedullary nail decreases the bending force on the hip joint by 25 to $30 \%$. This has advantage in elderly age group to make them weight bear earlier. Thus risk of life threatening complications like basal pneumonia and Deep Vein Thrombosis are reduced.
We had guide pin breakage in one patient while drilling for lag screw and the guide pincouldn't be retrieved. Since the broken guide pin is within the femoral head, it does not interfere with the hip movements. So we have to avoid the guide pin crossing the hip jointbecause if the guide pin breaks it will be difficult to retrieve from the acetabulum.

We encountered difficulty in passing derotation screw in 3 cases. In these cases the guide pin was going along the superior aspect of the neck. It was dealt by passing 130degree nail instead of 135degree.

In few cases, on passing the nail the fracture got distracted.In these cases the fracture was reduced and temporarily stabilized with a $2 \mathrm{~mm}$ ' $\mathrm{K}$ ' wire passed along the anterior cortex so as not to interfere with the passage of nail.

In 3 cases we had varus reduction. This couldhave been prevented by increasing the traction while advancing the nail, or by removing the guide pin from the femoral head and abducting the lower limb.

In our study, 9 of our patients had abductor lurch which gradually decrease with time.

We had shortening of $3 \mathrm{~cm}$ in one case, $2 \mathrm{~cm}$ in two cases, $1 \mathrm{~cm}$ in three cases.The shortening is managed with sole raise in 3 cases.

There were 3 cases with failure of derotation screw at the junction of threaded portion and the screw shaft. Among the three, one patient had varus reduction, one had distraction at the fracture site, one patient had associated nail breakage with fracture in varusmal union from premature weight bearing. The patient with implant failure attended the OPD after around 5 months. Eventhough the patient had implant failure with malunion, the patient had a good functional outcome.

\section{Conclusion}

We conclude that the PFN is a significant advancement in the treatment of unstable trochenteric fractures which has the unique advantages of closed reduction, preservation of fracture hematoma, less tissue damage, early rehabilitation 
and early return to work. Osteo synthesis using a PFN, used in unstable trochanteric fractures, resulted in low rates of clinical complications, excellent stabilization, few mechanical complications and adequate functional results. Thus the treatment of unstable intertrochanteric fracture with PFN had a more favourable outcome and it is the ideal implant of choice for unstable intertrochanteric fractures at present. 